\title{
Editorial: Benchmarking Biodiversity in an Era of Rapid Change
}

\author{
W. Douglas Robinson ${ }^{1 *}$ and Carlos A. Peres ${ }^{2}$ \\ ${ }^{1}$ Oak Creek Lab of Biology, Department of Fisheries, Wildlife and Conservation Sciences, Oregon State University, Corvallis, \\ OR, United States, ${ }^{2}$ School of Environmental Sciences, University of East Anglia, Norwich, United Kingdom
}

Keywords: biodiversity baselines, benchmarking biodiversity, environmental change, monitoring wildlife, conservation

\section{Editorial on the Research Topic}

Benchmarking Biodiversity in an Era of Rapid Change

\section{OPEN ACCESS}

Edited and reviewed by:

Orsolya Valkó,

Hungarian Academy of

Science, Hungary

*Correspondence:

W. Douglas Robinson

douglas.robinson@oregonstate.edu

Specialty section:

This article was submitted to

Conservation and Restoration

Ecology,

a section of the journal

Frontiers in Ecology and Evolution

Received: 06 November 2021 Accepted: 16 November 2021 Published: 02 December 2021

Citation:

Robinson WD and Peres CA (2021)

Editorial: Benchmarking Biodiversity in an Era of Rapid Change.

Front. Ecol. Evol. 9:810287.

doi: 10.3389/fevo.2021.810287
Human activities are amplifying the dynamic nature of Earth's climate and reshaping its landscapes and ecosystems (Ellis et al., 2020), justifying a preeminent need to characterize, identify, quantify, map, and archive data on all forms of terrestrial and aquatic biodiversity (Magurran et al., 2010). Several global efforts have indexed the status of biodiversity but typically at coarse levels of spatial resolution (e.g., the IUCN Red List). Highly endangered species are sometimes understood in great detail, but their roles in contemporary ecosystems are usually comparatively minor. For the vast majority of Earth's biodiversity, even basic taxonomy is poorly resolved (Winfree et al., 2015). Meanwhile, patterns of distribution, abundance and shifting community composition remain poorly quantified even for many of the best-known organisms (Magurran et al., 2018). How shall we truly understand biodiversity responses to environmental change without the anchor of adequate baselines?

In this special issue we introduce different perspectives on benchmarking biodiversity. Benchmarking is the creation of baseline measurements of distribution, abundance, genetic characteristics, and ecological roles of biodiversity. Beyond monitoring studies and one-off characterizations of baselines, benchmarking intentionally uses precisely repeatable methods and archives detailed data to maximize alignment with future replication, thereby promoting rigorous quantification of change through time (Robinson and Curtis, 2020). Widespread use of highly repeatable survey and counting methods can have the obvious benefit of unequivocally demonstrating how biodiversity responds to climate and other forms of inevitable change (Robinson et al., 2020). Given rapidly improving information on taxonomy, the rise of collaborative efforts with citizen scientists, massive public online databases, and GPS-based mapping, we live in an era when reliably benchmarking Earth's biodiversity is not only more feasible than ever but should be one of society's top priorities.

Aside from providing opportunities for future generations to rigorously quantify change, benchmarking biodiversity also creates opportunities for human improvement. It rewards skilled naturalists for their expertise (Tewksbury et al., 2014), improves training of new generations of scientists and the public to improve their understanding of the ecological roles and importance of diverse organisms (Theobald et al., 2015), facilitates current academic investigation of theoretical and empirical ideas (Dornelas et al., 2014; Gotelli et al., 2017), helps society improve their temporal perspective on natural and human-facilitated environmental change (Willis and Birks, 2006), and informs data-driven policy decisions affecting management and societal priorities (Santamaría and Méndez, 2012).

Although this special issue focuses on distribution, abundance, and genetics, present-day knowledge acquisition on a variety of aspects of biodiversity is sorely needed. Knowledge gaps 
have been categorized into eight groups: (i) Linnean (taxonomic discrepancies), (ii) Wallacean (species distributions), (iii) Prestonian (population ecology), (iv) Darwinian (species evolution), (v) Raunkiaeran (species traits), (vi) Hutchinsonian (abiotic tolerances), (vii) Eltonian (species interactions) (Hortal et al., 2015), and (viii) Parkerian shortfalls (Lees et al., 2020). These shortfalls in knowledge, when addressed adequately through careful collection of basic natural history knowledge combined with detailed evaluation of population, genomic and physiological information, may be remedied with systematic spatially-explicit species inventories and abundance information (Hortal et al., 2015).

The eight papers in this special issue inform topics tied directly to benchmarking biodiversity. Major gaps in our understanding of even some of the most charismatic, popular and most widely observed organisms, such as birds, are demonstrated by the near total absence of rigorous local abundance data for the most diverse continent, South America (Robinson, Errichetti et al.). A call for expanding a currently small $(N=6)$ network of large survey plots (100 ha or larger) to make precisely repeatable community inventories and abundance measurements is a feasible plan. Likewise, contemporary society has been put on alert recently that insect populations may be declining globally, yet we have few long-term benchmarking data available. Debates about trends and quantities of change are best settled with data. Standardizing reliable methods is a critical initial step. Montgomery et al. establish such standards for benchmarking insect populations. Beyond whole organisms, responses of genes and genomes to change are rarely evaluated in the context of short-term dynamics, yet we now have the technical means to analyze genetic samples from the distant past, now and to preserve them for future evaluation as technical knowledge improves (García and Robinson). Benchmarking biodiversity is an enormous task that may be enhanced with widespread public collaboration as internet-based opportunities expand interactive data archival resources. Contributions by untrained observers raise concerns, especially with abundance estimation,

\section{REFERENCES}

Dornelas, M., Gotelli, N. J., McGill, B., Shimadzu, H., Moyes, F., Sievers, C., et al. (2014). Assemblage time series reveal biodiversity change but not systematic loss. Science 344, 296-299. doi: 10.1126/science. 1248484

Ellis, E. C., Beusen, A. H. W., and Goldewijk, K. K. (2020). Anthropogenic biomes: 10,000 BCE to 2015 CE. Land 9:129. doi: 10.3390/land9050129

Gotelli, N. J., Shimadzu, H., Dornelas, M., McGill, B., Moyes, F., and Magurran, A. E. (2017). Community-level regulation of temporal trends in biodiversity. Sci. Adv. 3:e1700315. doi: 10.1126/sciadv.1700315

Hortal, J., de Bello, F., Diniz-Filho, J. A. F., Lewinsohn, T. M., Lobo, J. M., and Ladle, R. J. (2015). Seven shortfalls that beset large-scale knowledge of biodiversity. Ann. Rev. Ecol. Evol. Syst. 46, 523-549. doi: 10.1146/annurev-ecolsys-112414-054400

Lees, A. C., Rosenberg, K. V., Ruiz-Gutierrez, V., Marsden, S., Schulenberg, T. S., and Rodewald, A. D. (2020). A roadmap to identifying and filling shortfalls in neotropical ornithology. Auk 137:ukaa048. doi: 10.1093/auk/ukaa048

Magurran, A. E., Baillie, S. R., Buckland, S. T., Dick, J. P., Elston, D. A., Scott, E. M., et al. (2010). Long-term datasets in biodiversity research and monitoring: as demonstrated in a rare comparison of bird abundance data gathered by professionals and amateur birders (Robinson, Hallman et al.). Likewise, new technologies may facilitate better data collection and assessment of errors, as well as push measurements toward estimates of density and even population sizes, as demonstrated with camera traps (Green et al.). Moving forward, benchmark data allow assessments of geographic range shifts (Wilson et al.) and comparisons of biodiversity change as a function of disturbances, from smaller scale events such as mining (Lynggaard et al.) to extensive ones such as wildfires (Catullo et al.).

Time is ripe for appreciating the value of carefully collected, vetted biodiversity data gathered with precisely repeatable methods to allow humanity the best chance to understand how life responds to change on our dynamic planet. The longer we postpone the political will to undertake this task at a meaningful scale, the more incomplete our best baselines will become, and the more expensive measures to restore wild nature will become.

\section{AUTHOR CONTRIBUTIONS}

WR and CP wrote the manuscript, edited the manuscript, and administered the Research Topic collection. Both authors contributed to the article and approved the submitted version.

\section{FUNDING}

WR was supported by the College of Agricultural Sciences and the Mace Professorship at Oregon State University.

\section{ACKNOWLEDGMENTS}

We thank all authors and reviewers that contributed to this Research Topic and the staff at Frontiers in Ecology and Evolution for their administrative support throughout this process. assessing change in ecological communities through time. Trends Ecol. Evolut. 25, 574-582. doi: 10.1016/j.tree.2010.06.016

Magurran, A. E., Deacon, A. E., Moyes, F., Shimadzu, H., Dornelas, M., Phillip, D. A. T., et al. (2018). Divergent biodiversity change within ecosystems. Proc. Natl. Acad. Sci. U.S.A. 115, 1843-1847. doi: 10.1073/pnas.1712594115

Robinson, W. D., and Curtis, J. R. (2020). Creating benchmark measurements of tropical forest bird communities in large plots. Condor 122:duaa015. doi: 10.1093/condor/duaa015

Robinson, W. D., Hallman, T. A., and Curtis, J. R. (2020). Benchmarking the avian diversity of Oregon in an era of rapid change. Northwestern Naturalist 101, 180-193. doi: 10.1898/1051-1733-101.3.180

Santamaría, L., and Méndez, P. F. (2012). Evolution in biodiversity policy - current gaps and future needs. Evolut. Applic. 5, 202-218. doi: 10.1111/j.1752-4571.2011.00229.x

Tewksbury, J. J., Anderson, J. G. T., Bakker, J. D., Billo, T. J., Dunwiddie, P. W., Groom, M. J., et al. (2014). Natural history's place in science and society. BioScience 64, 300-310. doi: 10.1093/biosci/biu032

Theobald, E. J., Ettinger, A. K., Burgess, H. K., DeBey, L. B., Schmidt, N. R., Froehlich, H. E., et al. (2015). Global change and local solutions: Tapping the 
unrealized potential of citizen science for biodiversity research. Biol. Conserv. 181, 236-244. doi: 10.1016/j.biocon.2014.10.021

Willis, K. J., and Birks, H. J. B. (2006). What is natural? The need for a long-term perspective in biodiversity conservation. Science 314, 1261-1265. doi: $10.1126 /$ science. 1122667

Winfree, R., Fox, J. W., Williams, N. M., Reilly, J. R., and Cariveau, D. P. (2015). Abundance of common species, not species richness, drives delivery of a real-world ecosystem service. Ecol. Lett. 18, 626-635. doi: 10.1111/ele.12424

Conflict of Interest: The authors declare that the research was conducted in the absence of any commercial or financial relationships that could be construed as a potential conflict of interest.
Publisher's Note: All claims expressed in this article are solely those of the authors and do not necessarily represent those of their affiliated organizations, or those of the publisher, the editors and the reviewers. Any product that may be evaluated in this article, or claim that may be made by its manufacturer, is not guaranteed or endorsed by the publisher.

Copyright $\odot 2021$ Robinson and Peres. This is an open-access article distributed under the terms of the Creative Commons Attribution License (CC BY). The use, distribution or reproduction in other forums is permitted, provided the original author(s) and the copyright owner(s) are credited and that the original publication in this journal is cited, in accordance with accepted academic practice. No use, distribution or reproduction is permitted which does not comply with these terms. 